\title{
O processamento da anáfora pronominal em crianças com transtorno de déficit de atenção e hiperatividade e em crianças disléxicas: um estudo através da análise dos movimentos oculares
}

\author{
The processing of pronominal anaphora by children that have attention deficit hyperactivity \\ disorder or dyslexia: a study through the analysis of eye movements
}

\author{
Angela Inês Klein \\ Universidade Tecnológica Federal do Paraná - Ponta Grossa - Paraná - Brasil \\ André Krügel \\ Sarah Risse \\ Günter Esser \\ Ralf Engbert \\ Universidade de Potsdam - Potsdam - Alemanha \\ Vera Wannmacher Pereira \\ Pontifícia Universidade Católica do Rio Grande do Sul - Porto Alegre - Rio Grande do Sul - Brasil
}

$\diamond$

\begin{abstract}
Resumo: Nesta pesquisa propõe-se verificar o processamento da anáfora pronominal em crianças com transtorno de déficit de atenção e hiperatividade e em crianças disléxicas. A pesquisa foi realizada com 75 crianças falantes de Língua Alemã como língua materna, as quais leram dois textos de 80 palavras cada um deles, contendo anáforas pronominais. Os movimentos oculares de todos os participantes foram gravados e, para certificação de uma leitura com atenção, foram realizadas duas atividades que testaram a compreesão em leitura. Através da análise dos movimentos oculares, mais especificamente das fixações, os dados indicam que as crianças com transtornos têm dificuldade em processar a anáfora pronominal, em especial as crianças disléxicas.
\end{abstract}

Palavras-chave: TDAH; Dislexia; Compreensão em leitura; Movimentos oculares; Anáfora pronominal

\begin{abstract}
The aim of this work was to verify the processing of pronominal anaphora by children that have attention deficit hyperactivity disorder or dyslexia. The sample studied consisted of 75 children that speak German, which read two texts of 80 words containing pronominal anaphora. The eye movements of all participants were recorded and, to make sure they were reading with attention, two activities that tested reading comprehension were proposed. Through the analysis of eye movements, specifically the fixations, the data indicate that children with disorders have difficulty to process the pronominal anaphora, especially dyslexic children.
\end{abstract}

Keywords: ADHD; Dyslexia; Reading comprehension; Eye movements; Pronominal anaphora

\section{Introdução}

Para compreender um texto, o leitor precisa agregar informação nova ao dado velho e ao mesmo tempo combinar diferentes tipos de informação: fonológica, sintática, semântica e pragmática, o que exige complexa atividade cognitiva e alto desempenho mnemônico. Caso haja presença de anáforas no texto, o leitor precisa selecionar o antecedente correto a fim de torná-lo coeso. Realizar essa integração de diferentes partes do texto demonstra uma habilidade leitora.

O objetivo deste estudo é verificar o processamento da anáfora pronominal em crianças com transtorno de déficit de atenção e hiperatividade (TDAH) e em crianças disléxicas. Para tanto hipotetiza-se que as crianças com transtornos apresentam dificuldades para processar 
anáforas pronominais. Essa dificuldade pode se evidenciar à medida que as crianças com transtornos fixam as anáforas por um tempo superior se comparado às demais palavras dos textos. A fim de testar esta hipótese foram analisados os movimentos oculares, mais especificamente a duração da fixação gaze, pois o comportamento dos olhos durante a leitura, seja a direção (para a direita ou para a esquerda) e a velocidade (rápido ou lento) em que se movem ou como são realizados os saltos (curtos ou compridos) revelam indicadores sobre o processamento da informação, neste caso, acerca da anáfora pronominal.

\section{Transtorno de Déficit de Atenção e Hiperatividade e dislexia}

Crianças com TDAH e crianças disléxicas são descritas como indivíduos que apresentam dificuldades específicas da linguagem, isto é, nelas está afetada a habilidade de aprender determinado aspecto da linguagem. Enquanto que em disléxicas há um déficit relacionado ao aprendizado da língua escrita, nas com TDAH mostram-se dificuldades de atenção e concentração que se refletem na vida acadêmica. O que esses dois grupos têm em comum são dificuldades de aprendizagem e de recordar descrições, bem como déficit na memória operacional (DIGHE e KETTLES, 1996; MCLOUGHLIN, FITZGIBBON e YOUNG, 1994; HULME e MACKENZIE, 1992).

A dislexia é conceituada como um transtorno de leitura de ordem biológica que interfere na aprendizagem da leitura, da escrita e da ortografia (BELL et al., 2003). As crianças com esse transtorno apresentam distorções, substituições e omissões durante a leitura em voz alta e silenciosa. (AMERICAN PSYCHIATRIC ASSOCIATION, 2000). De acordo com Padget et al. (1996), sujeitos com dislexia exibem dificuldades na linguagem oral, déficit na memória de curto prazo, baixos escores em compreensão em leitura, expressão escrita pobre e dificuldade em organizar informação.

Já Rayner et al. (2012) definem o transtorno de leitura sob outro ângulo, sendo para eles uma incapacidade específica da linguagem com origem neurobiológica. É caracterizado por dificuldades na acurácia e fluência de reconhecimento de palavras e habilidade baixa de decodificação e soletração. Essas dificuldades normalmente são resultado de um déficit no componente fonológico da linguagem, que muitas vezes não é necessário a outras habilidades cognitivas. Outras consequências incluem problemas com a compreensão em leitura e redução da experiência em leitura, o que impede o aumento de vocabulário e conhecimento (RAYNER et al., 2012).

O TDAH, por outro lado, é caracterizado por Rohde e Mattos (2003) pela desatenção, hiperatividade e impulsividade, características estas que afetam o desempenho acadêmico, os relacionamentos familiar e social, o ajustamento psicossocial e a vida profissional.

Segundo Barkley (2002), as pessoas com TDAH apresentam problemas no Executivo Central e não um transtorno de inteligência ou conhecimento. O Executivo Central é caracterizado como Sistema Atencional Supervisor, que controla a resposta aos estímulos, flexibiliza a seleção de comportamentos, envolvendo planejamento, monitoração e ajuste das respostas relacionadas aos planos e intenções do sujeito. Esse componente é uma das partes da memória operacional (BADDLEY, 2003).

\section{Anáfora pronominal}

Anáfora pronominal é a anáfora mais encontrada tanto na linguagem oral quanto na escrita. Em estudos realizados na língua inglesa, "pronomes como ela, ele, eles são as anáforas mais comuns" (COULSON, 1995, p.93). Embora seja uma palavra que revele uma nova informação sobre uma ideia já mencionada anteriormente, ela é produzida espontaneamente pelas crianças, o que motivou o estudo da compreensão da mesma em textos.

Ao se lerem os exemplos (1), (2) e (3), nota-se que eles têm algumas características em comum: retomam um sintagma nominal, remetem à mesma entidade discursiva e por si só não têm uma denotação, ou seja, são praticamente vazios semanticamente.

(1) Arthur $r_{i}$ brigou com a vizinha. Ele ${ }_{i}$ estava muito nervoso.

(2) Qualquer pessoa $a_{i}$ fica feliz quando o trabalho dela $a_{i}$ é elogiado.

(3) Eu adoro acampar . Isso $_{i}$ me lembra a infância.

No exemplo (1) sabe-se apenas que o leitor deve "procurar a informação em outro lugar" (FÁVERO, 1997), ou seja, encontrar um correferente substantivo masculino e singular. Nesse exemplo os requisitos exigidos pelo pronome ele são preenchidos por Arthur.

Não somente o pronome pessoal é considerado uma anáfora pronominal ao retomar um sintagma nominal, como nos exemplos (1) e (2), mas também o pronome demonstrativo em (3) é uma anáfora à medida que dá pistas ao leitor sobre o correferente correto.

A fim de ter uma compreensão total de uma sentença, o leitor precisa muitas vezes relacionar diferentes partes do texto. Caso ele leia, por exemplo, "sim, ele adora comê-las de manhã" indica que uma pessoa do sexo masculino adora comer algo. Mas, se a sentença continuar da seguinte forma: "André gosta de frutas?", a partir desse momento, o leitor sabe que ele se refere a André e que frutas é o que ele gosta de comer. Neste texto "ele" e "las" 
são anáforas: palavras que dependem do contexto para terem o seu sentido completo.

Processar a anáfora, nesta pesquisa, implica um processo de resolução da mesma, ou seja, deve ocorrer uma correferenciação quando uma pessoa, um objeto ou uma ideia é relacionada à anáfora. Note que o processo de resolução é parte do processamento da linguagem, e, por consequência, do sistema cognitivo que se encontra no cérebro. A informação entra na forma de palavras pelo sistema visual para o significado ser analisado. Portanto, a resolução de anáforas é um aspecto de um processamento mais amplo.

\section{Movimentos oculares}

Os movimentos oculares resumem-se a dois tipos: as sacadas progressivas ou regressivas e as fixações. Cada um apresenta características bem próprias e evidencia determinados processos cognitivos.

De acordo com Rayner (1998), as fixações são breves períodos de tempo durante os quais o olho permanece examinando uma pequena área do estímulo. Cada fixação dura em média 250 milésimos de segundo e dificilmente ocorre mais de uma vez em palavras curtas (duas ou 3 letras), mas acontecem mais frequentemente em palavras longas. No entanto, quando a leitura é silenciosa, o tempo de fixação dura em média 225 milissegundos. O local, o número e o tempo das fixações podem variar, sendo esses dados vitais para análise dos processos cognitivos envolvidos na leitura de um texto.

Já as sacadas podem ser divididas em progressivas ou regressivas. Os movimentos sacádicos progressivos são os pulos que o olho faz de uma fixação até a próxima fixação. Nos intervalos dessas fixações ocorre o escaneamento e processamento da informação. Rayner (1998) afirma que, na leitura, as sacadas apresentam comprimento médio de 7 a 9 letras, mas podem variar de 1 até 18 letras. Já as sacadas regressivas são movimentos sacádicos realizados no sentido oposto ao da leitura. Macedo et al. (2008) diz que provavelmente regressões ocorrem de 10 a $15 \%$ de vezes na leitura e servem como uma forma de conferir se uma palavra foi pulada ou se não foi compreendida. As sacadas podem ser analisadas em função do seu comprimento, da duração, da localização e da direção dos movimentos.

Com os dados provenientes de fixações e sacadas é possível monitorar o olhar humano. Esse olhar permite, além de compreender melhor o funcionamento do próprio aparato visual, estabelecer indicadores confiáveis dos processos atencionais. (MAIA, 2008)

As características dos movimentos oculares mudam de acordo com a idade. Os movimentos oculares das crianças são diferentes dos movimentos dos adultos, por exemplo. Kowler e Martins (1985) realizaram um estudo em que compararam crianças pré-escolares com adultos na visualização de uma cena. As crianças realizaram mais sacadas pequenas e drifts durante uma fixação; a latência das sacadas foi em geral mais longa; e os movimentos sacádicos foram menos precisos.

De acordo com Rayner (1998) o campo visual, ou seja, todo o espaço abrangido pela visão quando focamos um objeto, está dividido em três regiões: foveal, parafoveal e periférica. Na região foveal vê-se o estímulo de forma clara. Ela é responsável pela zona de processamento do detalhe e abrange 2 graus de ângulo visual (na leitura, 1 grau equivale a 3-4 caracteres). Já a zona parafoveal corresponde a 5 graus à volta do ponto fixado, é a zona da qual ainda se consegue tirar alguma informação que possa ser importante para o processamento do estímulo. E, por último, a zona periférica, a qual não é útil para o processamento do detalhe, é a área além da região parafoveal.

A função primária da sacada é trazer uma nova parte do texto para a região foveal, a fim de esta ser analisada com detalhe, porque com a região parafoveal ou periférica isso é uma tarefa difícil ou impossível (RAYNER e BERTERA, 1979; RAYNER, IMHOFF, MORRISON, SLOWIACZEK e BERTERA, 1981). Considerando que a maioria das palavras em um texto são fixadas durante a leitura, muitas palavras são ignoradas, isto é, saltadas, de modo que o processamento foveal de cada palavra não é necessário. Por exemplo, palavras de conteúdo são fixadas cerca de $85 \%$ do tempo, enquanto que palavras funcionais são fixadas cerca de $35 \%$ do tempo. (CARPENTER e JUST, 1983; RAYNER e DUFFY, 1986). Palavras de função são fixadas com menos frequência do que palavras de conteúdo, porque elas tendem a ser curtas, e há uma clara relação entre a probabilidade de fixar uma palavra e seu comprimento: à medida que aumenta o comprimento da palavra, a probabilidade de fixá-la aumenta; palavras com 2-3 letras são fixadas apenas em torno de $25 \%$ do tempo, enquanto que palavras com 8 letras ou mais são quase sempre fixadas (e muitas vezes fixadas mais de uma vez).

$\mathrm{Na}$ literatura atualmente argui-se sobre a melhor forma de medir o tempo necessário para o processamento de determinada informação a fim de poder entender o processo cognitivo envolvido. Quando o estudo está focado no nível além da palavra (sentença ou parágrafo), distingue-se entre primeira ${ }^{1}$ leitura (a leitura inicial, que consiste em todas as fixações da primeira leitura) e segunda leitura (releitura). Para tanto, precisa estar claro que o tempo total de leitura pode levar em consideração somente a primeira leitura ou também a releitura. Por

\footnotetext{
1 Em inglês o termo é denominado first-pass e second-pass.
} 
outro lado, quando se trata de estudos em nível da palavra, medir o tempo total despendido para a leitura torna-se um pouco mais simples; no entanto, como resolver quando a palavra é saltada, isto é, não fixada? Ou como avaliar quando há duas fixações na mesma palavra? As medidas mais usadas nesses casos são a duração do olhar ${ }^{2}$ (representa a soma de tempo de todas as fixações numa palavra) e a duração da primeira fixação ${ }^{3}$ (é a duração da primeira fixação em uma palavra, independentemente se é a fixação apenas de uma palavra ou a primeira de múltiplas fixações). Enquanto a duração da primeira fixação é uma medida de acesso lexical, a duração do olhar reflete o processo de integração do texto (INHOFF, 1984).

A aquisição de informação visual necessária para a leitura parece que ocorre nos primeiros $50-70 \mathrm{~ms}$ de fixação. Os olhos escaneiam letra por letra durante a fixação, por isso o leitor é capaz de perceber quando ocorre repentinamente mudança de uma letra, por exemplo (RAYNER, 1998).

A cada fixação, o leitor tem uma área perceptiva ${ }^{4}$ de onde ele extrai informação. Essa área corresponde a 3-4 espaços de letra à esquerda do ponto de fixação e 14-15 espaços de letra à direita. Rayner (1986) descobriu que leitores iniciantes têm uma área perceptiva menor (aproximadamente 12 espaços de letras à direita da fixação) que leitores proficientes (14-15 espaços de letras). O tamanho da área perceptiva também varia de acordo com a dificuldade do texto. Rayner (1986) realizou um estudo com crianças de quarta série. Quando as crianças leram um texto que estava adequado ao seu nível de conhecimento, a área perceptiva foi similar à de adultos. Entretanto, quando essas crianças receberam textos de nível universitário, a área perceptiva foi bem menor. Também Kliegl e Engbert (2005) verificaram que os movimentos oculares de crianças são diferentes dos movimentos dos adultos. Por exemplo, crianças realizam mais e menores sacadas, permitem que ocorram pequenos movimentos (drifts) durante uma fixação, elas demoram mais para iniciar uma sacada e também elas são menos acuradas que os adultos em controlar os movimentos dos seus olhos. Assim que elas vão envelhecendo, os movimentos oculares vão se tornando mais exatos e controlados (RAYNER, 1998).

Leitores não adquirem informação somente à esquerda da fixação; pesquisas evidenciam que leitores adquirem também informações parciais à direita através da visão parafoveal de partes de palavras. A fixação das três primeiras letras da próxima palavra inicia o processamento do acesso lexical (RAYNER, 1989). A

\footnotetext{
Em inglês - gaze duration.

3 Em inglês first fixation duration.

4 Em inglês span perceptual.
}

visão parafoveal é capaz de extrair informação suficiente de palavras curtas, identificando-as e, consequentemente, não as fixando.

Ao extrair uma informação parcial da palavra através da visão parafoveal, o leitor precisa integrar de alguma maneira essa informação com a subsequente fixação, a qual é feita pela fóvea. Quando se lê, não se vê determinada parte do texto por cerca de $250 \mathrm{~ms}$ devido a um espaço ou período em branco resultante da sacada. Esse tempo é necessário até os olhos alcançarem a parte subsequente do texto e realizarem uma nova fixação. No entanto, o cérebro torna os inputs tão discretos que não se tem consciência desse período e ele mantém uma visão coerente do texto que está sendo lido. Por isso a presente autora acredita ser importante trabalhar em nível de texto, e não somente com frases ou palavras, pois o texto é o meio de aquirir informação mais difundido na escola. Texto não é um aglomerado de frases, portanto estudos com texto exigem outras habilidades cognitivas do leitor.

Por que o leitor salta determinadas palavras num texto? Saltar uma palavra significa não fixá-la. Sabe-se que a restrição contextual tem um grande efeito; palavras de conteúdo restrito de acordo com o contexto precedente são menos fixadas em comparação com palavras que não são restritas (RAYNER e WELL, 1996). Também palavras com alta frequência na língua são mais saltadas do que palavras que aparecem pouco (RAYNER et al., 1996 e Kliegl e Engbert (2005). Contudo, o que mais influencia uma palavra ser saltada é o seu comprimento. Palavras curtas são muito mais propensas a serem ignoradas do que palavras longas (KLIEGL e ENGBERT, 2005). Isso sugere que, quando um leitor salta uma palavra, ele a identifica na fixação prévia através da visão parafoveal. Por isso ocorrem curtas fixações antes de uma palavra ser saltada (KLIEGL e ENGBERT, 2005).

O tempo de fixação na região de um pronome varia de acordo com a facilidade que o leitor tem de relacionar o pronome e seu antecedente (EHRLICH e RAYNER, 1983), pois processamento anafórico consiste em realizar uma integração.

Certamente existem diferenças individuais quando se trata dos movimentos oculares durante a leitura. Leitores disléxicos são caracterizados como plodders (aqueles que se movem lentamente) e exploradores por Olson, Kliegl, Davidson e Foltz (1985). Plodders fazem relativamente poucas sacadas progressivas e pouquíssimas regressões, enquanto que os exploradores saltam com mais frequência palavras, fazem mais sacadas progressivas longas e também mais regressões.

Leitores disléxicos, assim como leitores não hábeis e iniciantes, fazem longas fixações, sacadas curtas, mais fixações e mais regressões se comparados com leitores normais (EDEN, STEIN, WOOD e WOOD, 1994). 
Munoz, Armstrong, Hampton e Moore (2003) propuseram que crianças e adultos com TDAH apresentam movimentos oculares únicos, principalmente em tarefas de rastreamento visual as quais requerem inibição de sacadas automáticas. No estudo sujeitos entre 6 e 59 anos realizaram duas tarefas: uma pró-sacada ${ }^{5}$, em que os sujeitos deveriam olhar para o estímulo alvo; e outra antissacada ${ }^{6}$, em que eles não deveriam olhar o alvo, isto é, deveriam ignorá-lo. Resultados mostraram que sujeitos com TDAH tiveram reações de tempo mais longas, sacadas mais lentas na tarefa de pró-sacada em comparação com o grupo controle. Já na tarefa de antissacada, os participantes com TDAH tiveram mais dificuldades de inibir o olhar, o tempo de reação também foi mais longo.

Outros pesquisadores têm encontrado resultados parecidos, o que indica padrões oculares característicos de sujeitos com TDAH. Feifel et al. (2004) verificaram que adultos com TDAH realizam mais sacadas antecipatórias que os sujeitos controle. Na tarefa de antissacada, sujeitos com o transtorno cometeram significativamente mais erros. Os adultos apresentaram déficits na inibição, aspecto já evidenciado em testes com crianças.

Thaler et al. (2009) examinaram a leitura em crianças disléxicas, crianças com problemas de atenção, crianças com ambos os transtornos e compararam os resultados com crianças com desenvolvimento normal. Foram examinados a acurácia leitora, a latência na nomeação e os padrões dos movimentos oculares durante a leitura de palavras simples. ${ }^{7}$ Os resultados indicam que crianças disléxicas evidenciaram um comprometimento na fluência leitora, mas não problemas de acurácia leitora. Em contrapartida, as crianças com comorbidade fizeram muito mais erros do que todos os demais grupos, mas mostraram menos problemas de fluência leitora que os disléxicos. A gravação dos movimentos oculares revelou que as crianças disléxicas fizeram o maior número de fixações, mas apresentaram fixações únicas (single fixations) mais curtas que as crianças portadoras dos dois transtornos. O comprimento da palavra foi o que teve o maior efeito em disléxicos, enquanto que a densidade do encontro consonantal nas palavras afetou todos os grupos da mesma forma.

Citando outros estudos que evidenciaram movimentos oculares particulares de crianças com TDAH e com crianças com transtorno de leitura (TL), apresentase a pesquisa de Deans et al. (2010), os quais realizaram um experimento com crianças entre 6 e 12 anos falantes de inglês. $\mathrm{O}$ objetivo dos autores era usar o rastreamento ocular como medida de diagnóstico clínico. O experimento consistia na leitura de cinco sentenças curtas. De modo geral, os resultados são os seguintes: as crianças disléxicas têm o tempo de leitura maior, as fixações são mais longas e realizam mais movimentos oculares atípicos se comparadas às crianças controle; crianças com TDAH também mostraram movimentos atípicos, como menos sacadas da esquerda para a direita se comparadas às do grupo controle. A diferença significativa entre os grupos com os transtornos mostrou-se em relação ao tempo total de leitura: crianças com TL têm uma leitura mais lenta. ${ }^{8}$

Além disso, Deans et al. (2010) compararam os resultados entre crianças medicadas e crianças que não haviam tomado a medicação durante a coleta de dados e verificaram que não há diferença significativa nos escores. Por outro lado, Mostofsky, Lasker, e Cutting (2001) também consideraram a influência da medicação no desempenho dos movimentos oculares de sujeitos com TDAH. Nesta última pesquisa, as crianças não medicadas mostraram maior latência nas sacadas, o que se opõe aos achados de Deans et al. (2010). ${ }^{9}$

\section{Amostragem}

A amostragem desta pesquisa está constituída de 75 crianças falantes de língua alemã como língua materna moradoras da cidade de Potsdam na Alemanha. Para a seleção das crianças foram levados em consideração os seguintes critérios:

1. as crianças tinham entre 8 e 12 anos;

2. as crianças com 8 anos frequentavam a terceira série do ensino fundamental, enquanto as demais crianças estavam divididas entre o quarto e o sexto ano de escolaridade; 10

3. todas as crianças com transtorno estavam em terapia;

4. tanto as crianças com o diagnóstico de dislexia quanto as crianças com TDAH precisavam estar diagnosticadas;

5. no dia do teste as crianças não tomaram medicação, caso alguma fizesse isso por orientação médica.

5 Pró-sacada significa uma sacada em direção ao alvo.

6 No experimento é requisitado ao sujeito olhar no sentido oposto ao estímulo visual. De forma geral, pode-se dizer que são sacadas fora de um alvo.

7 Simples aqui está em oposição a palavras compostas. Exemplos do teste:Palavras Curtas CVC: Esel (burro), Monat (mês); Palavras Curtas CCC Obst (fruta), Fisch (peixe); Palavras Longas CVC: Tierartz (veterinário) Teekanne (bule); Palavras Longas CCC: Salzdose (saleiro) Besenstiel (cabo de vassoura).

8 Os autores concluem o artigo dizendo que o Eye Tracker ainda não pode ser usado como medida de diagnóstico, pois, embora movimentos oculares característicos tenham sido mostrados por sujeitos com TDAH e com TL, ainda são necessárias mais pesquisas para corroborar os achados e apresentar mais diferenças entre os dois grupos.

9 Acreditando também em que haja diferença nos escores entre crianças medicadas e não medicadas, foi feita a opção por testar as crianças não estando medicadas.

${ }^{10}$ A escolha dessa série como ponto de partida deve-se ao fato de os alunos geralmente apresentarem conhecimentos suficientes para realizarem uma leitura fluente. 
Além disso, terem obtido escores dentro da média nos seguintes subtestes de inteligência da bateria de testes BUEGA $(2008)^{11}$ :

6. teste de quociente de inteligência não verbal;

7. teste de leitura;

8. teste de concentração BP;

9. teste de ortografia.

\section{Especificações técnicas do aparelho}

O sistema utilizado no estudo experimental, que mediu o movimento dos olhos das crianças, é um Eyelink 1000. Esse equipamento foi configurado para o modo monocular e registra a posição, o movimento e a duração do olho direito. Uma fonte de luz infravermelha mede o tamanho e a posição da pupila e a reflexão da córnea. É gerada uma amostra a cada $1 \mathrm{~ms}(1000 \mathrm{~Hz})$, o que o caracteriza como um rastreador ocular rápido. O software que interagiu com o Eyelink a fim de reproduzir os textos lidos e as figuras na tela do computador denomina-se Matlab R2008a.

\section{Descrição do instrumento}

O instrumento está constituído de dois textos narrativos de 80 palavras em alemão. Em ambos os textos há 10 anáforas pronominais. Para cada texto foram desenhadas 6 figuras e criadas 10 perguntas de compreensão, todas se referindo especificamente a um pronome no texto. Além disso, um teste de compreensão em leitura foi fundamental a fim de induzir as crianças a realizarem uma leitura com atenção durante $o$ experimento, isto é, este teste minimizou a possibilidade de os alunos simplesmente passarem os olhos pelo texto e, por isso, não manifestarem os reais movimentos oculares durante uma leitura.

A fim de dar ao leitor deste estudo clareza das anáforas analisadas, apresenta-se a seguir um dos textos de compreensão, bem como a tradução do mesmo para o português.

TеXто I em alemão. Apenas para facilitar a visualização, optou-se aqui por sublinhar as anáforas analisadas.

In einem Ort nahe dem Meer wohnte Tim mit seiner Oma. Das Wahrzeichen ihres Ortes war eine goldene Krone, die in einer Truhe versteckt wurde. Der Pirat Rotbart erfuhr von ihr und stahl sie in tiefster Nacht. Mit seiner Mannschaft feierte und becherte er die

\footnotetext{
11 BUEGA é um "Diagnóstico Básico de Distúrbios de Desenvolvimento em Idade Escolar" utilizado na Alemanha. Foi desenvolvido e padronizado por G. Esser, A. Wyschkon e K. Ballaschk.
}

ganze Nacht. Tim erwachte von dem Lärm und schlich mit seinen Freunden am Morgen in die Kabine von Rotbart. Sie stahlen seine Hose und die Krone. Das ganze Dorf lachte über die gepunktete Unterhose des Piraten.

Tradução para o português do TEXTO I:

Em um lugar perto do mar morava Tim com sua avó. $\mathrm{O}$ ponto de referência da cidade deles era uma coroa de ouro, a qual estava escondida dentro de um baú. O pirata Barba Vermelha descobriu-a e a roubou na calada da noite. Com seu grupo ele comemorou e bebeu a noite inteira. Tim acordou com o barulho e foi em silêncio com seus amigos de manhã na cabine do Barba Vermelha. Eles roubaram as calças dele e a coroa. Toda a vila riu das cuecas com bolinhas do pirata.

\section{Levantamento e tabulação dos dados}

O levantamento e a tabulação de dados foram feitos considerando a duração do olhar gaze, pois é o tipo de fixação mais indicado ao se pesquisar crianças, haja vista que esse tipo de fixação é a soma das fixações antes de o leitor deixar de fixar a palavra e, consequentemente, considera praticamente todas as fixações feitas pela criança numa primeira leitura, refletindo o processo de integração do texto (INHOFF, 1984) e também porque muitas das pesquisas citadas neste trabalho também consideraram a duração da fixação gaze para as análises (em especial os estudos de Rayner citados anteriormente).

A fim de facilitar a análise das fixações, na presente pesquisa em específico, por se tratar de um texto com oito linhas (não somente sentenças ou palavras), foi criado um parser a partir do programa Matlab R2008a. Esse parser considera somente a primeira leitura (First pass reading) e desmerece as trocas excessivas de linhas e saltos inconsistentes cometidos especialmente antes do início da leitura e/ou depois de terem fixado o ponto no final do texto, além de desconsiderar as microssacadas e as piscadas excessivas.

Além disso, houve necessidade de fazer mais alguns ajustes para melhor interpretar as fixações: a) as fixações da primeira e da última palavra de cada linha foram desconsideradas; $b$ ) no caso de a duração da single-fixation e da first-fixation ser mais curta que $80 \mathrm{~ms}$ ou mais longa que $1000 \mathrm{~ms}$, essa fixação também foi desconsiderada. A justificativa para isso vem do estudo de Just e Carpenter (1980), os quais afirmam que os leitores gastam mais tempo lendo as palavras finais de uma sentença, mas isso não é devido a características da palavra, mas porque toda a sentença é compreendida apenas no final. 


\section{Análise estatística}

Para fazer a análise estatística fez-se uso dos modelos mistos lineares (linear mixed models). Esses modelos possibilitam a análise dos dados com variáveis aleatórias. Através de um efeito randômico as seguintes variáveis puderam ser levadas em consideração para avaliar as fixações oculares:

1. Grupo TDAH;

2. Grupo dislexia;

3. Grupo controle;

4. Pronomes;

5. Pron+1 (a palavra logo após o pronome);

6. Palavras não alvo (todas as demais palavras dos textos);

7. Comprimento da palavra;

8. Frequência de uso da palavra na língua alemã ${ }^{12}$;

Os modelos mistos lineares $(\mathrm{mml})$ são a análise estatística mais indicada para este experimento psicolinguístico, pois, ao contrário de testes de ANOVA, por exemplo, estes não requerem amostras iguais. Exemplificando: o número das anáforas pronominais no texto é muito menor do que o de todas as demais palavras. Além disso, esses modelos estatísticos consideram todas as variáveis de forma paralela. Segundo Baayen et al. (2008), os mml têm oferecido soluções para vários problemas que afligem a pesquisa psicolinguística.

O Gráfico 1 apresenta os resultados da interação entre os três grupos (controle/com TDAH/Disléxicos) e as palavras dos textos (palavras não alvo/pronomes/ palavras logo após o pronome). Os resultados mostraram que não há uma interação significativa entre crianças com TDAH/ Controle e tempo de fixação das palavras do texto (no target/ pronomen/ pron+1), ou seja, as crianças com TDAH e as crianças controle apresentam variações parecidas no tempo de fixação nos três grupos de palavras.

No entanto, encontrou-se uma interação significativa entre crianças disléxicas e controle ao se comparar o tempo de fixação das palavras do texto (no target) com as anáforas (Pronoun): $\mathrm{b}=0,350, \mathrm{SE}=0,11, \mathrm{t}=3,17$, $\mathrm{p}<0,01$, bem como comparando as palavras não alvo (no target) com as palavras após a anáfora (Pron+1): $b=-0,187, S E=0,09, t=-2,10, p<0,05$. Isso significa que as crianças disléxicas, em comparação às crianças controle, apresentam claramente um tempo de fixação mais longo nos pronomes do que nas palavras não alvo. Nas palavras após o pronome, o tempo de fixação das disléxicas é reduzido se comparado ao das palavras não alvo.

Nas crianças controle não houve diferença significativa entre os tempos de fixação das palavras não alvo e das palavras seguidas ao pronome.

\footnotetext{
12 A frequência foi adquirida no site $<$ http:dlexdb.de $>$. O corpus está composto de 122 milhões de usos
}

Gráfico 1. Interação entre grupo e palavras alvo da duração da fixação gaze.

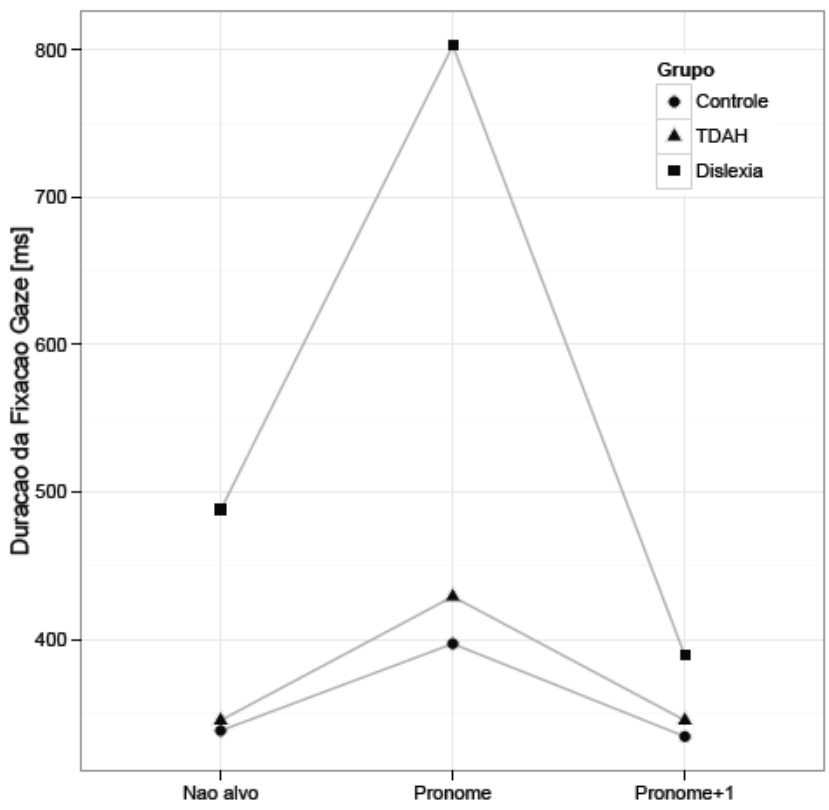

No início deste texto, apresentou-se a hipótese de crianças com TDAH e crianças disléxicas apresentarem dificuldades para processar anáforas pronominais. De acordo com o Gráfico 1, essa relação existe, ou seja, crianças disléxicas precisam de um tempo significativamente maior que as crianças controle para fixar as anáforas pronominais. Já quanto ao grupo com TDAH, não foi encontrada diferença significativa entre as crianças controle e as com TDAH, embora se visualize que crianças com TDAH precisam de mais tempo para processar o pronome. Assim conclui-se que essa hipótese é confirmada, pois ambos os grupos com transtorno gastam mais tempo fixando o pronome, caracterizando uma dificuldade, mesmo que se tenha evidenciado uma diferença estatística significativa somente no grupo das crianças disléxicas.

Não foram encontradas pesquisas que conjuguem dislexia com anáforas. Há um estudo que analisa a interpretação do pronome de acordo com a teoria de Binding ou de correferenciação com crianças italianas disléxicas (FIORIN, 2010), mas esse autor não considera o processamento da anáfora em relação às demais palavras do texto, objetivo desta pesquisa. Além disso, o estudo dele foi a nível de sentença e este avalia a compreensão textual, podendo o resultado do mesmo não ser parâmetro para a presente pesquisa. Há também o estudo de Tops et al. (2011), que avalia a produção textual de crianças disléxicas falantes de holandês; entre outras dificuldades, os autores citam o uso errado de palavras de referência, de anáforas, como em "A vaca, ele dá leite" ao invés de "A vaca, ela dá leite" (p. 15). No entanto, a produção implica um processo cognitivo diferente do que a compreensão, 
e por isso também não é possível comparar o presente estudo aos resultados do Tops et al.

\section{Discussão dos resultados}

Por que as crianças disléxicas necessitam de tanto tempo para processar a anáfora pronominal? Crianças disléxicas apresentam limitações na memória operacional, mais especificamente no componente fonológico da linguagem, que leva a dificuldades de aprendizagem. Jeffries e Everatt (2004) compararam crianças disléxicas com controle em atividades que avaliaram processamento fonológico, atividades viso-espaciais, motoras, funções executivas e inibitórias. As disléxicas tiveram um desempenho inferior apenas nas atividades fonológicas. Assim os autores concluíram que crianças com esse transtorno têm uma memória operacional deficiente. McLoughlin et al. (2002) inclusive definem o transtorno com base na memória operacional: "a dislexia do desenvolvimento é uma herança genética e neurológica determinada por uma ineficiência na memória operacional, que tem um particular impacto na comunicação verbal e escrita".

Mostrou-se nesta pesquisa que as crianças disléxicas gastam muito mais tempo fixando os pronomes se comparadas às controle e às com TDAH, mesmo essa classe sendo constituída de palavras menores que substantivos, adjetivos e verbos, que foi o pronome. Recuperar um antecedente de uma expressão referencial parece realmente ser uma atividade complexa, que exige muito da memória operacional e talvez o processamento cognitivo da leitura ainda não esteja tão automatizado.

Como o Gráfico 1 evidencia, há uma diferença nos escores das crianças com TDAH e disléxicas. A justificativa para isso talvez seja devido aos déficits diferenciados que as crianças com transtornos apresentam na memória operacional. Enquanto as com TDAH têm uma limitação no Executivo Central (BARKLEY, 2002) as com dislexia mostram um déficit no componente fonológico da linguagem (RAYNER et al., 2012). E, como a investigação era de cunho linguístico, a complexidade em resolver a anáfora se evidenciou nos participantes disléxicos; já os com TDAH, cujo problema é a atenção, souberam lidar com essa deficiência, porque foi lhes oferecido um ambiente adequado para realizar o teste.

Assim, os dados indicam que as crianças disléxicas apresentam limitações linguísticas, provavelmente decorrentes do déficit no componente fonológico da memória operacional. Em contrapartida, as crianças com TDAH, mesmo tendo problemas com o Executivo Central, o que levaria a crer numa dificuldade em relação à anáfora e seu antecedente, mostraram apenas uma pequena dificuldade em efetuar o processamento do pronome, mas que não chega a ser significativa.

\section{Conclusão}

Por que somente as crianças disléxicas (e não as com TDAH) demandaram tempo significativamente superior em relação às crianças sem transtornos para processar a anáfora pronominal, já que ambos os grupos apresentam limitações na memória operacional? A justificativa para isso talvez seja devido aos déficits diferenciados que esses grupos apresentam na memória operacional. Enquanto as com TDAH têm uma limitação no Executivo Central (BARKLEY, 2002) as com dislexia mostram um déficit na componente fonológico da linguagem (RAYNER et al., 2012). As crianças com TDAH tiveram a variável atenção manipulada, pois o teste foi breve num ambiente pequeno e silencioso. Em contrapartida, as crianças disléxicas, que têm dificuldades relacionadas à linguagem, seu déficit no componente fonológico da linguagem continuou existindo ao realizarem a leitura dos textos.

Futuros pesquisadores talvez se interessem em investigar crianças com TDAH ao distanciar mais o antecedente da anáfora, pois o antecedente precisa estar disponível na memória operacional, e por isso ele precisa continuar ativado a fim de a resolução ser rápida e bem sucedida. Daí poderia se sugerir, por exemplo, que quanto maior a distância entre antecedente e anáfora, mais difícil seria de relacionar os dois, e dificuldades em processar o pronome em crianças com TDAH talvez também iriam se evidenciar.

Estudando a anáfora pronominal pode-se analisar o processamento da linguagem, pois há questões sintáticas e semânticas envolvidas para compreendê-la adequadamente, o que nos leva a questionar a natureza da linguagem, sua representação e processamento.

\section{Referências}

American Psychiatric Association, Diagnostic and Statistical Manual of Mental Disorders. 4. ed. Text Revision. Washington, DC, 2000.

BAAYEN, R. H.; DAVIDSON, D. J.; BATES, D. M. Mixed-effects modeling with crossed random effects for subjects and items. Journal of Memory and Language, v. 59, p. 390-412, 2008. http:// dx.doi.org/10.1016/j.jml.2007.12.005

BADDELEY, A. D. Working memory and language: An overview. Journal of Communication Disorders, v. 36, n. 3, p. 189-208, 2003. http://dx.doi.org/10.1016/S0021-9924(03)00019-4

BARKLEY, R. Transtorno de Déficit de Atenção/hiperatividade. São Paulo: ArtMed, 2002.

CARPENTER, P. A.; JUST, M. A. What your eyes do while your mind is reading. In: RAYNER, $\mathrm{K}$. (Ed.). Eye movements in reading: Perceptual and language processes. New York: Academic. 1983.

COULSON, Mrk. Anaphoric reference. In: GREENE, Judith; COULSON, Mark (Ed.). Language understanding: currente issues. Buckinghan: Open University Press, 1995.

DEANS, P.; O'LAUGHLIN, L.; BRUBAKER, B.; GAY, N.; KRUG, D. Use of Eye Movement Tracking in the Differential 
Diagnosis of Attention Deficit Hyperactivity Disorder (ADHD) and Reading Disability. Psychology, v. 1, p. 238-246, 2010. http://dx.doi. org/10.4236/psych.2010.14032

DIGHE, A.; KETTLES, G. Developmental dyspraxia: an overview. In: REID, G. (Ed.). Dimensions of dyslexia.Edinburgh: Moray House Publications. 1996. Vol.2: Literacy, language and learning. p. 231-263.

EDEN, G. F.; STEIN, J. F.; WOOD, M. H.; WOOD, F. B. Differences in Eye Movements and Reading Problems in Dyslexic and Normal Children. Vision Research, v. 34, n. 10, p. 1345-1358, 1994. http:// dx.doi.org/10.1016/0042-6989(94)90209-7

EHRLICH, K.; RAYNER, K. Pronoun assignment and semantic integration during reading: Eye movements and immediacy of processing. Journal of Verbal Learning and Verbal Behavior, v. 22, p. 75-87, 1983. http://dx.doi.org/10.1016/S0022-5371(83)80007-3

FÁVERO, Leonor Lopes. Coesão e coerência textuais. São Paulo: Ática, 1997.

FEIFEL, D.; FARBER, R. H.; CLEMENTZ, B. A.; PERRY, W.; ANLLO-VENTO, L. Inhibitory Deficits in Ocular Motor Behavior in Adults with Attention-Deficit Hyperactivity Disorder. Biological Psychiatry, v. 56, n. 5, p. 333-340, 2004. http://dx.doi.org/10.1016/ j.biopsych.2004.06.019

FIORIN, G. Meaning and Dyslexia: A Study on Pronouns, Aspect, and Quantification. 2010. Disponível em: <http://igitur-archive. library.uu.nl/dissertations/2010-0624-200159/fiorin.pdf>. Acessado em: 6 dez. 2012

HULME, C.; MACKENZIE, S. Working memory and severe learning difficulties. Hove: Lawrence Erlbaum Associates, Publishers. 1992.

INHOFF, A. W. Two stages of word processing during eye fixations in the reading of prose. Journal of Verbal Learning and Verbal Behavior, v. 23, p. 612-624, 1984. http://dx.doi.org/10.1016/S00225371(84)90382-7

JEFFRIES, S.; EVERATT, J. Working Memory: Its Role in Dyslexia and Other Specific Learning difficulties. Dyslexia, v. 10, n. 3, p. 196-214, 2004. http://dx.doi.org/10.1002/dys.278

JUST, M.A.; CARPENTER, P.A. A theory of reading: from eye fixations to comprehension. Psychological Review, v. 87, p. 329-354, 1980. http://dx.doi.org/10.1037/0033-295X.87.4.329

KLIEGL, R.; ENGBERT, R. Fixation Durations before Word Skipping in Reading, Psychonomic Bulletin e Review, v. 12, n. 1, p. 132-138, 2005. http://dx.doi.org/10.3758/BF03196358

KOWLER, E.; MARTINS, A. J. Eye movements of preschool children. Science, v. 215, p. 997-999, 1985. http://dx.doi.org/ 10.1126/science.7156979

MACEDO, E.C.; YOKOMIZO, J.E.; LUKASOVA, K.; FONTELES, D. S. R. Movimentos sacádicos durante leitura de texto em crianças e universitários bons leitores. Mundo Saúde, n. 32, v. 2, p. 131-138, 2008.

MAIA, M. Processos bottom-up e top-down no rastreamento ocular de imagens. Veredas - Revista de Estudos Linguísticos, Juiz de Fora, n. 2 , p. $08-23,2008$

MCLOUGHLIN, D.; FITZGIBBON, G. e YOUNG, V. Adult dyslexia: Assessment, counselling and training. London: Whurr Publishers Ltd. 1994.

MCLOUGHLIN, D.; LEATHER, C.; STRINGER, P. The Adult Dyslexic. Interventions and Outcomes. London: Whurr, 2002.

MOSTOFSKY, S. H.; LASKER, A. G.; CUTTING, L. E. Oculomotor Abnormalities in Attention Deficit Hyperactivity Disorder: A Preliminary Study. Neurology, v. 57, n. 3, p. 423-430, 2001. http://dx.doi.org/10.1212/WNL.57.3.423
MUNOZ, D. P.; ARMSTRONG, I. T.; HAMPTON, K. A.; MOORE, K. D. Altered Control of Visual Fixation and Saccadic Eye Movements in Attention-Deficit Hyperactivity Disorder, Journal of Neurophysiology, v. 90, n. 1, p. 503-515, 2003. http://dx.doi. org/10.1152/jn.00192.2003

OAKHILL, J.; YUILL, N. Pronoun Resolution in Skilled and LessSkilled Comprehenders: Effects of Memory Load and Inferential Complexity. Language and Speech, v. 29, p. 25-37, 1986.

OLSON, R. K.; KLIEGL, R.; DAVIDSON, B. J.; FOLTZ, G. Individual differences and developmental differences in reading disability. In: MACKINNON, G.; WALLER, T. G. (Ed.). Reading research: Advances in theory and practice. New York: Academic Press, 1985. p. 1-64.

PADGET, S. Y.; KNIGHT, D. F.; SAWYER, D. J. Tennessee meets the Challenge of Dyslexia, Annals of Dyslexia, v. 46, n. 1, p. 51-72, 1996. http://dx.doi.org/10.1007/BF02648171

RAYNER, K.; BERTERA, J. H. Reading without a fovea. Science, v. 206 , p. 468,1979 . http://dx.doi.org/10.1126/science.504987

RAYNER, K.; DUFFY, S. A. Lexical complexity and fixation times in reading: Effects of word frequency, verb complexity, and lexical ambiguity. Memory e Cognition, v. 14, p. 191-201, 1986. http:// dx.doi.org/10.3758/BF03197692

RAYNER, K.; WELL, A. D. Effects of contextual constraint on eye movements in reading: A further examination. Psychonomic Bulletin e Review, v. 3, p. 504-509, 1996.

RAYNER, K. Eye movements and the perceptual span in beginning and skilled readers. Journal of Experimental Child Psychology, v. 41, p. 211-236, 1986. http://dx.doi.org/10.1016/0022-0965(86)90037-8

RAYNER, K. Eye Movements in Reading and Information Processing: 20 Years of Research, Psychological Bulletin, v. 124, n. 3, p. 372-422, 1998. http://dx.doi.org/10.1037/00332909.124.3.372

RAYNER, K. Language processes: Unfulfilled promises. Contemporary Psychology, v. 34, p. 384-385, 1989. http://dx.doi. org/10.1037/027915

RAYNER, K.; INHOFF, A. W.; MORRISON, R.; SLOWIACZEK, M. L.; BERTERA, J. H. Masking of foveal and parafoveal vision during eye fixations in reading. Journal of Experimental Psychology: Human Perception and Performance, v. 7, p. 167-179, 1981. http:// dx.doi.org/10.1037/0096-1523.7.1.167

RAYNER, K.; POLLATSEK, A.; ASHBY, J.; CLIFTON, C. Psychology of Reading. 2. ed. New York: Psychology Press, 2012.

ROHDE L. A.; MATTOS P. Princípios e práticas em TDAH. Porto Alegre: Artes Médicas, 2003.

THALER, V.; URTON, K.; HEINE, A.; HAWELKA, S.; ENGL, V.; JACOBS, A. M. Different behavioral and eye movement patterns of dyslexic readers with and without attentional deficits during single word reading. Neuropsichologie, v. 47, n. 1009, p. 2436-1445, 2009. http://dx.doi.org/10.1016/j.neuropsychologia.2009.04.006

TOPS, W.; CALLENS, C.; VAN CAUWENBERGHE, E.; ADRIAENS, J.; BRYSBAERT, M. Beyond spelling: The writing skills of students with dyslexia in higher education. Ghent University, Belgium. 2011

Recebido: 30 de Agosto de 2014

Aprovado: 05 de Novembro de 2014

Contatos: angelaklein@utfpr.edu.br kruegel@uni-potsdam.de sarah.risse@uni-potsdam.de vpereira@pucrs.br gesser@uni-potsdam.de ralf.engbert@uni-potsdam.de 